\title{
Miscarriage hospitalisations: a national population-based study of incidence and outcomes, 2005-2016
}

\author{
Indra San Lazaro Campillo ${ }^{1,2^{*}}$ D, Sarah Meaney ${ }^{1,2}$, Keelin O'Donoghue ${ }^{1,3}$ and Paul Corcoran 2,4
}

\begin{abstract}
Background: Early miscarriage is one of the most common obstetric causes of maternal morbidity early in pregnancy. However, data concerning non-fatal complications among hospitalisations for early miscarriage are lacking. The aim of this study was to determine whether there were changes in the incidence, management and outcomes of early miscarriage hospitalisations between 2005 and 2016.

Methods: This is a nationwide population-based study of 50,538 hospitalisations with a diagnosis of early miscarriage of all acute maternity hospitals in Ireland. Electronic health records were retrieved using the Hospital In-Patient Enquiry database. Main outcomes include the incidence rates of hospitalisations and management for early miscarriage, and rates of blood transfusion and length of stay over 2 days.

Results: Overall, 50,538 hospitalisations for early miscarriage were identified from 2005 to 2016. The risk of hospitalisation decreased from 70.6 per 1000 deliveries (95\% Cl 68.4 to 72.8) in 2005 to 49.7 per 1000 deliveries (95\% Cl 49.7 to 53.3) in 2016; however, the risk of blood transfusion increased over time (ratio: 2.0; 95\% Cl 1.6 to 2.4). Women of advanced maternal age had a higher risk of hospitalisations. There were less blood transfusions among women who undertook medical treatment (ratio: $0.3 ; 95 \% \mathrm{Cl} 0.1$ to 0.5 ), but they had an increased risk of staying over 2 days at the hospital (ratio: $1.5 ; 95 \% \mathrm{Cl} 1.2$ to 1.9) compared to evacuation of retained products of conception.

Conclusions: Hospitalisation rates for early miscarriage decreased over time with an increase in risk of blood transfusion and an extended length of stay at the hospital. Women who underwent medical management did not have as many blood transfusions as those undergoing surgical management. However, they had an increased risk of an extended stay. Research is needed to explore both outpatient and inpatient settings in order to improve the management and care provided.
\end{abstract}

Keywords: Miscarriage, Hospitalisations, Rates, Morbidity

\section{Plain English summary}

Approximately, 1 out of 4 women will experience an early miscarriage in their reproductive life. Despite the burden of early miscarriage, there is a lack of information regarding trends in incidence rates of hospitalisations and type of management of early miscarriage, but also about the morbidities associated to hospitalisations

\footnotetext{
* Correspondence: indra.campillo@ucc.ie

${ }^{1}$ Pregnancy Loss Research Group, The Irish Centre for Fetal and Neonatal Translational Research University College Cork, Cork, Ireland

${ }^{2}$ National Perinatal Epidemiology Centre, Department of Obstetrics and Gynaecology, University College Cork, Cork University Maternity Hospital, 5th floor, Postgraduate Study Room, 5S-30, Wilton, Cork T12 YE02, Ireland
} Full list of author information is available at the end of the article of early miscarriage. Therefore, the objectives of this study were to explore national trends in incidence rates of hospital admissions for early miscarriage in the Republic of Ireland from January of 2005 to December of 2016, and to estimate morbidity associated with blood transfusion and length of stay over 2 days.

This is a retrospective population-based study using the Hospital In-Patient Enquiry (HIPE). The HIPE is a computer-based system designed to collect demographic, clinical and administrative data on discharges and deaths in the Republic of Ireland. However data from the emergency department and outpatient settings are not available. 
Over this period of time there were approximately 50,000 hospitalisations for early miscarriage. Early miscarriage hospitalisations became $19 \%$ less common during 2005-2016 but the risk of blood transfusion doubled. The risk of an extended length of stay also increased over the same time period. Women who underwent medical management did not have as many blood transfusions compare to those who had surgical management. However, women who underwent medical treatment had a higher risk of a prolonged stay at the hospital. More research is needed to explore the patterns of care and morbidities associated to hospitalisation in order to improve protocols of management and the care provided for women who miscarry.

\section{Background}

Miscarriage is one of the most common complication in early pregnancy [1-3]. It is clinically classified as either early miscarriage, within 13 weeks of gestation, or late miscarriage, between 13 and before 24 completed weeks of pregnancy $[1,4-6]$. Early miscarriage occurs in 10 to $30 \%$ of all pregnancies $[7,8]$ and in 11 to $16 \%$ of all clinically recognised pregnancies $[9,10]$. Late miscarriage is estimated to occur in less than $1 \%[11,12]$. Despite the burden of early miscarriage, to our knowledge, no studies have published national trends in incidence rates of hospitalisations for early miscarriage.

The pathways of care for early miscarriage have evolved [13]. Traditionally, the "gold standard treatment" for early miscarriage was surgical uterine evacuation [6]. The introduction and improvement in sensitivity of transvaginal scans (TVS) has helped to diagnose miscarriage early in pregnancy $[6,14]$. Furthermore, medical management, using misoprostol [15], and expectant management are acceptable alternative to surgery, which are currently offered to haemodynamically stable patients $[13,16]$. However, the optimal management for miscarriage and their associated adverse effects are still being investigated [17].

Hospitalisations during pregnancy are indicative of severe complications [18]. Early miscarriage is associated with less severe complications than ectopic pregnancy [19]; however, heavy bleeding is one of the clinical complications why women who miscarry are admitted to hospital [6, 20]. Moreover, second-trimester miscarriage, while less common, almost always requires inpatient admission and senior obstetric input [11]. Yet, clear and generalised evidence concerning morbidities among hospitalisations for early miscarriage are lacking [21]. Therefore, this study aimed to explore national trends in incidence rates of hospitalisations for early miscarriage, to explore trends in management, and to estimate the associated morbidity of blood transfusion and length of stay.

\section{Methods}

\section{Study design and data source}

A retrospective population-based study was conducted using the Hospital In-Patient Enquiry (HIPE) database. All inpatient admissions for early miscarriage in all public maternity hospital settings in the Republic of Ireland from January 1st 2005 to 31st December 2016 were included. The HIPE is an anonymous national health computer-based system designed to collect demographic, clinical and administrative data on discharges and deaths from all 62 acute hospitals in the Republic of Ireland [22, 23]. Therefore, outpatient data, (i.e. emergengcy department, day patient, early pregnancy assessment units or post-anaesthetic care department) are not available [22, 23]. Outpatient and inpatient data are not linked at a national level in the Republic of Ireland, and therefore, this study was unable to report how many hospitalisation of early miscarriage were referred from emergency department or other outpatient settings. The Economic and Social Research Institute on behalf of the Health Service Executive is the executive organism which administerd and managed the HIPE database [24].

\section{Population}

From 2005, the 10th Revision Australian modification of International Statistical Classification of Disease and Related Health Problems (ICD-10-AM) and the Australian Refined Diagnosis Related Groups are the coding classification systems of diagnosis used in the HIPE system [22]. All miscarriage hospitalisations within the HIPE dataset were identified using the diagnostic codes for outcome of miscarriage (O03). The unit of analysis was the annual number of delivery discharges within the HIPE dataset using the diagnostic code for outcome of delivery (Z37). According to the ICD-10-AM, miscarriage is defined as the spontaneous expulsion or extraction of the productos of conception by any means, before viability, that being less than 22nd weeks of pregnancy. Miscarriage can be classified as complete miscarriage (i.e. when productos of conception are not evident on ultrasound), but also incomplete miscarriage (i.e. when patient is admitted because of retained products of conception). However, HIPE data does not specify gestational age in single weeks but uses ranges between $<5,5$ to 13,14 to 19 , 20 to 25,26 to 33 and 34 to 36 completed weeks of gestation. Therefore, our analysis were restricted to early miscarriage, which was defined as a miscarriage before 14 completed weeks.

\section{Outcomes measures and independent variables}

This study included blood transfusion as a complication and length of stay as an indicator of efficiency. 
Diagnostic codes for blood transfusion were identified using codes within the HIPE dataset $(920,600$ \& $9,206,200 \& 1,370,601-1,370,603)$. Length of stay was automatically obtained using the menu of the HIPE database. Hospitalisations with length of stay greater than 2 days were also considered a complication for the purpose of this study.

Demographic and pregnancy-related variables within the HIPE dataset included year of discharge, maternal age (in years) and public or private health insurance. All women who are pregnant and ordinarily resident in the Republic of Ireland are entitled to free maternity care, covering antenatal visits, labour and delivery and postnatal care under the Maternity and Infant Care Scheme [25]. Those inpatient admissions who were treated under the Maternity and Infant Care Scheme were classified as public patients. The only alternative option is to be treated using private health insurance were classified as private patients.

Management for early miscarriage was categorised as surgical and medical treatment. Women were classified as being managed expectantly when neither of the previous procedures codes were identified (i.e. other treatments) or when women had no recorded procedures in HIPE. Surgical treatment included evacuation of retained products of conception. Evacuation of retained products of conception applied when a code for one of the following procedures was recorded: curettage of uterus with $(D \& C)$ or without dilatation $(3,564,300,35,640-00$ \& 35,640-01), suction curettage of uterus $(3,564,003 \& 3,564,301)$, dilation and evacuation of uterus (D\&E) (35643-03). Medical treatment of early miscarriage involving specific types of prostaglandin E1 (i.e. misoprostol and cervagem) or mifepristone could not be identified as no procedure codes are recorded in HIPE to indicate administration of these drugs. Instead, medical management using codes for prostaglandin, as a general group, or oxytocin were used as the reference medical treatment for early miscarriage. A more detailed description of the principal procedures codes is included in Additional file 1.

In the Republic of Ireland, women with no signs of infection (i.e. vaginal discharge), excessive bleeding, pyrexia or abdominal pain are offered expectant or medical management from the outpatient departments. Surgical management of early miscarriage should be offered to women who make a specific request, who change their mind during the course of conservative or medical management, who have heavy bleeding and/or severe pain, when gestational trophoblastic disease is suspected or when infected intrauterine tissue is present [6].

\section{Statistical analysis}

Hospitalisation incidence rates were estimated using the annual number of inpatient discharges for early miscarriage divided by the annual number of delivieries in the Republic of Ireland over the 12-year period (2005-2016). The crude and adjusted incidence rate ratio of hospitalisation for early miscarriage with $95 \%$ confidence intervals $(\mathrm{CI})$ were calculated using univariate and multivariable Poisson regression. All analyses were adjusted by year of discharge, maternal age, public versus private patient and weeks of gestation. The crude and adjusted incidence rate ratio with 95\% CI for blood transfusion and length of stay over 2 days was calculated using a multivariable Poisson regression model. Data analysis was performed using Stata software (version 12) and IBM SPSS Statistics for Windows (version 21.0).

\section{Results}

In total, 50,538 hospitalisations for early miscarriage up to 14 completed weeks of gestation and 801,764 deliveries were identified between January 2005 and December 2016. Overall, the rate for hospitalisation of early miscarriage was 63.0/1000 deliveries (95\% CI 62.5 to 63.6; Table 1$)$. Approximately $59.0 \%(n=29,835)$ of early miscarriages were diagnosed as incomplete miscarriage. Almost $99.4 \%$ of all women admitted to maternity hospitals were between 5 to 13 weeks of gestation $(n=50,252)$.

The rates for women with early miscarriage decreased from 70.6/1000 deliveries (95\% CI 68.4 to 72.8) in 2005 to an incidence rate of 51.5/1000 deliveries (95\% CI 49.7 to 53.3) in 2016 (Fig. 1). The risk of being hospitalised for early miscarriage increased steadily with age, with the exception of women aged between 25 to 29 years old, who had a lower risk (adjusted incidence rate ratio $0.61 ; 95 \%$ CI 0.59 to 0.63 ). Women of 40 years of age or older had approximately a three-fold increaded risk of being hospitalised than women younger than 25 years old (adjusted incidence rate ratio 3.34; 95\% CI 3.22 to 3.45). Public patients had almost double the risk of being hospitalised compared to private patients (Table 1).

Among hospitalisations for early miscarriage over the same time period, evacuation of retained products of conception was undertaken in almost half of the total sample ( $n=22,897 ; 45.3 \%)$, and only $2.8 \%$ were medically managed $(n=1404)$. Half of the women were expectantly managed $(n=26,225 ; 51.9 \%)$; among those, only $3.5 \%$ had other type of treatment $(n=914)$. Expectant management remained the most frequent type of treatment over the study period (Fig. 1). Evacuation of retained products of conception gradually decreased from 38.0/ 1000 deliveries (95\% CI 36.4 to 39.6) in 2005 to 22.3 / 1000 deliveries (95\% CI 21.1 to 23.5) in 2016. Medical management steadily increased over time from $0.4 / 1000$ deliveries (95\% CI 0.2 to 0.5$)$ in 2005 to $1.6 / 1000$ deliveries (95\% CI 1.3 to 1.9) in 2016 (Fig. 1). The average length of stay for early miscarriage fluctuated during the 12-year period from 1.3 days (SD 0.8) in 2005 to 1.2 (SD 
Table 1 Incidence rate and incidence rate ratio of hospitalisations for early miscarriage in the Republic of Ireland, 2005-2016

\begin{tabular}{|c|c|c|c|c|c|}
\hline & Deliveries & $\begin{array}{l}\text { No of hospitalisations for early } \\
\text { miscarriage }\end{array}$ & $\operatorname{Rate}^{\mathrm{a}}(95 \% \mathrm{Cl})$ & $\begin{array}{l}\text { Crude incidence rate ratio } \\
(95 \% \mathrm{Cl})\end{array}$ & $\begin{array}{l}\text { Adjusted incidence rate ratio }{ }^{b} \\
(95 \% \mathrm{Cl})\end{array}$ \\
\hline$\overline{\text { All }}$ & 801,764 & 50,538 & \multicolumn{3}{|l|}{$63.0(62.5-63.6)$} \\
\hline \multicolumn{6}{|c|}{ Year } \\
\hline $\begin{array}{l}2005- \\
2008\end{array}$ & 257,750 & 17,958 & $69.7(68.7-70.7)$ & 1.0 (ref. group) & 1.0 (ref. group) \\
\hline $\begin{array}{l}2009- \\
2012\end{array}$ & 285,751 & 17,956 & $62.8(61.9-63.8)$ & $0.93(0.91-0.95)$ & $0.85(0.84-0.88)$ \\
\hline $\begin{array}{l}2013- \\
2016\end{array}$ & 258,263 & 14,624 & $56.6(55.7-57.5)$ & $0.95(0.93-0.97)$ & $0.77(0.75-0.78)$ \\
\hline \multicolumn{6}{|c|}{ Maternal Age } \\
\hline$<25$ & 109,812 & 6404 & $58.3(56.9-59.7)$ & 1.0 (ref. group) & 1.0 (ref. group) \\
\hline $25-29$ & 177,647 & 9071 & $51.1(50.0-52.1)$ & $0.60(0.58-0.62)$ & $0.61(0.59-0.63)$ \\
\hline $30-34$ & 281,961 & 14,697 & $52.1(51.3-53.0)$ & $0.90(0.87-0.92)$ & $1.10(1.02-1.10)$ \\
\hline $35-39$ & 191,970 & 14,250 & $74.2(73.0-75.4)$ & $1.27(1.24-1.31)$ & $1.60(1.55-1.65)$ \\
\hline $40+$ & 40,374 & 6116 & $\begin{array}{l}151.5(147.7- \\
155.3)\end{array}$ & $2.60(2.51-2.69)$ & $3.34(3.22-3.45)$ \\
\hline \multicolumn{6}{|c|}{ Health insurance } \\
\hline Private & 200,014 & 8951 & $44.8(43.8-45.7)$ & 1.0 (ref. group) & 1.0 (ref. group) \\
\hline Public & 601,750 & 41,587 & $69.1(68.4-69.8)$ & $1.38(1.35-1.41)$ & $1.87(1.83-1.92)$ \\
\hline
\end{tabular}

${ }^{a}$ Rate per 1000 deliveries; ${ }^{b}$ Adjusted incidence rate ratio from multivariable analysis including all variables in the table

0.7 ) days in 2016; with an overall average of 1.2 days (SD

$0.7)$ (Fig. 2). Approximately $86.4 \%(n=43,679)$ of inpatients for early miscarriage stayed in hospital for 1 day and $10.0 \%(n=5049)$ stayed for 2 days, with only $3.6 \%$ $(n=1810)$ having a length of stay of more than 2 days.
Among the 50,538 hospitalisations for early miscarriage, $554(1.1 \%)$ had a blood transfusion and 1810 (3.6\%) had a length of stay longer than 2 days (Table 2). The risk of blood transfusion among hospitalisations for early miscarriage increased over time. No significant

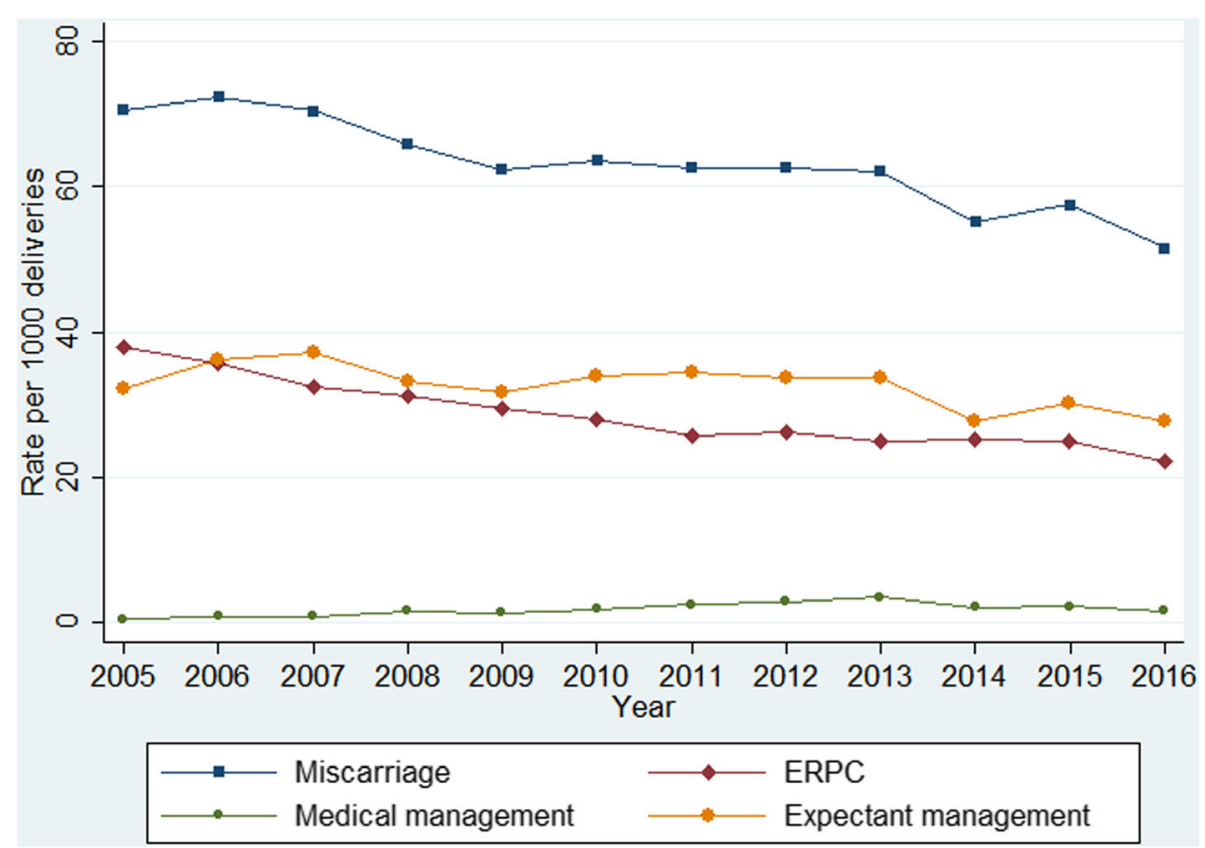

Fig. 1 National hospitalisation rates for early miscarriage and type of management 


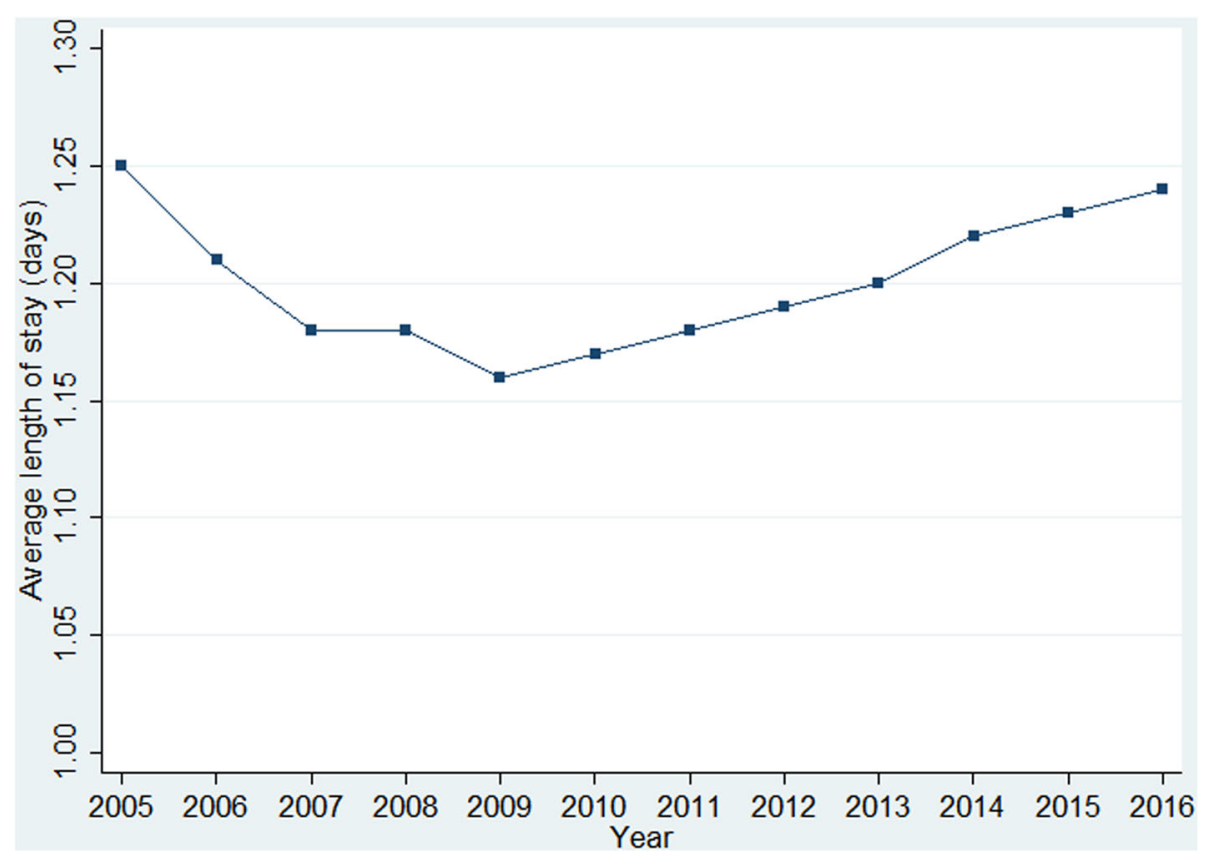

Fig. 2 Average length of stay (days) of hospitalisations for early miscarriage

differences were found for maternal age and risk of blood transfusion, except for those women who were 25 to 29 years old compared to those younger than 25 years old. Public patients had more than double the risk of a blood transfusion than private patients (adjusted incidence rate ratio $2.5 ; 95 \%$ CI 1.9 to 3.3 ). Women who were medically, expectantly treated or who had another type of treatment had less blood transfusions as those undergoing evacuation of retained products of conception (adjusted incidence rate ratio 0.3; CI 0.1 to 0.5 \& adjusted incidence rate ratio $0.3 ; 95 \% \mathrm{CI} 0.2$ to 0.4 respectively). Incomplete miscarriage had almost two times the rate of blood transfusion compared to early miscarriage (adjusted incidence rate ratio $1.5 ; 95 \%$ CI 1.1 to 2.0 ; Table 2).

The incidence rate ratio for length of stay over 2 days among hospitalisations for early miscarriage was reduced from 2009 to 2012 compared to 2005-2008 and was increased from 2013 to 2016 compared to 2005-2008 (Table 2). The risk of a prolonged stay at the hospital was reduced with advanced maternal age. Public patients had almost twice the risk of having a length of stay over 2 days than private patients (adjusted incidence rate ratio 1.7 ; $95 \%$ CI 1.5 to 1.9 ; Table 2). Women who were medically treated had almost twice the risk of having a length of stay over 2 days compared to those undergoing evacuation of retained products of conception (adjusted incidence rate ratio 1.5 ; CI 1.2 to 1.9). Women who were expectantly treated or who had another type of treatment were less likely to have a prolonged stay at the hospital compared to those treated with evacuation of retained products of conception (Table 2). Finally, no significant differences were found between complete and incomplete miscarriage and the risk of an extended stay at the hospital.

\section{Discussion}

This is a population-based study including more than 50 thousand hospitalisations for early miscarriage. The incidence of early miscarriage hospitalisations became 19\% less common during 2005-2016, but the risk of blood transfusion doubled. Women aged 40 years or older had a three-fold risk of hospitalisation than those aged 25 years; and public patients had twice the rate. Women undergoing medical management did not have as many blood transfusion as those undergoing evacuation of retained products of conception; whereas it increased the risk of length of stay over 2 days. Incomplete miscarriage was associated with an increased risk of blood transfusion.

It is well-documented that older maternal age is a risk factor for adverse pregnancy outcomes [26-28] and this is further supported by the results in our study. For example,

the maternal and fetal loss cohort study in Denmark also found that women in their late 30 s or older had a higher risk of having ectopic pregnancy, miscarriage or stillbirth, irrespective of their reproductive history [28]. We found no other study assessing the possible impact of health insurance coverage on the risk of complications among hospital admissions for early miscarriage. In order to promote a equal provision of care to 
Table 2 Blood transfusion and length of stay over 2 days for hospitalisations of early miscarriage, 2005-2016

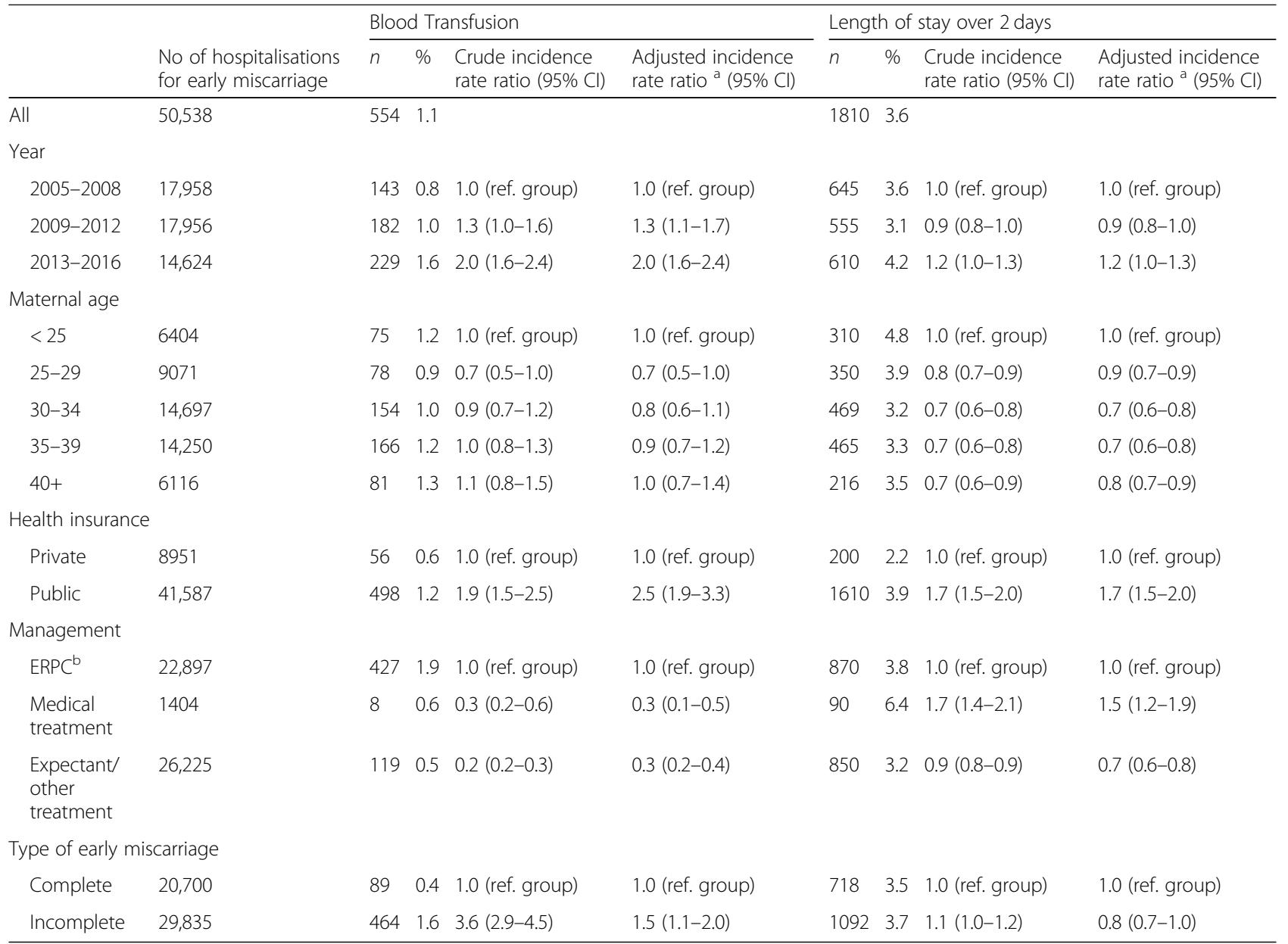

${ }^{\mathrm{a}}$ Adjusted incidence rate ratio from multivariable analysis including all variables in the table; ${ }^{\mathrm{b}} E R P C$ Evacuation of retained products of conception

pregnant women who miscarry in hospital settings, this possible association should be investigated.

It is important to highlight the possible impact of the modification of the ultrasound values used to diagnose early miscarriage. This change was made to reduce false positive cases of early miscarriage (i.e. a patient who may have an early sonogram with unknown viability and another sonogram where fetal heart activity is found) at an international level in 2011, 2012 and 2013 by the Royal College of Obstetrician and Gynaecologists [29], the UK National Institute for Health and Care Excellence [30] and the American College of Radiology [31] respectively. As in other countries, the Royal College of Physicians of Ireland also modified their guidelines in $2011[6,32]$. One of the recommendations was to perform a second ultrasound scan to confirm the diagnosis of miscarriage when pregnancies are under 8 weeks of gestation [6]. Although the rate of hospitalisations was reducing before the guidelines, it is sometimes the case that guidelines are produced after a period of time when clinical practice has already been changing. For example, the reduction of the incidence of early miscarriage during 2005-2011 may suggest an improvement in early miscarriage diagnosis in the years leading up to the revised clinical guidance.

In contrast to our results, studies carried out by The National Institute for Health and Care Excellent found that women with a miscarriage who are managed expectantly have a higher risk of blood transfusion and more days of bleeding compared to those who have surgical treatment $[3,33]$. One possible explanation for these divergent results is that pregnant women with severe haemorrhage or pain were excluded from some randomized controlled trials [34-37]. Another explanation could be that we were unable to explore if women who were surgically managed had initially been expectantly or medically treated as an outpatient. For example, it is well-documented that there is a higher risk of bleeding and unplanned intervention after expectant or medical management compared to surgical treatment $(4,38)$; 
with medical management failure varying from 10 to $20 \%[15,38]$.

The sample size of our study population is one of the main strength of this study. In addition, the HIPE data are recorded following standardised methods using the ICD-10-AM diagnosis code across all the hospitals [22]. Because single weeks of gestation were not available, analysis were restricted to early miscarriage before 14 completed weeks of gestation. Analysing second trimester miscarriage would have included pregnancy loss up to 25 completed weeks of gestation, resulting in the inclusion of a number of stillbirths rather than miscarriages in our analysis. A limitation of the study is that only inpatient data are available from the HIPE database [22]. As a result this study will under-estimate the overall burden of early miscarriage given the lack of outpatient data available nationally. However, this study will probably not under-estimate the morbidity as all were hospital based. In order to estimate the overall burden of early miscarriage, both outpatient and inpatient cases should be investigated.

In conclusion, maternal age, type of health insurance, type of treatment and incomplete miscarriage significantly affected the risk of blood transfusion and length of stay over 2 days at the hospital after being adjusted by confounders. However, a better understanding of the morbidities associated with early miscarriage hospitalisations is needed to improve management and care provided.

\section{Additional file}

Additional file 1: Diagnosis, procedures and complications codes for miscarriage. (DOCX $13 \mathrm{~kb})$

\section{Acknowledgements}

Not applicable.

\section{Funding}

This research received no specific grant from any funding agency in the public, commercial or not-for-profit sectors.

\section{Availability of data and materials}

Data are available with the permission of the Irish Healthcare Pricing Office.

\section{Authors' contributions}

All authors had a role in the conception of the study. P. C and I.S.L.C obtained, analysed and interpreted the data. S. M participated in data analysis, and S. M and K.O.D in the interpretation of results. We confirm that all authors included in this study participated in the drafting and have approved the manuscript for submission. This manuscript has not been published and is not under consideration for publication elsewhere.

\section{Ethics approval and consent to participate}

This study was exempt from the requirement of full ethical review as it used publicly available anonymised data.

Consent for publication

Not applicable.

\section{Competing interests}

The authors declare that they have no competing interests.

\section{Publisher's Note}

Springer Nature remains neutral with regard to jurisdictional claims in published maps and institutional affiliations.

\section{Author details}

${ }^{1}$ Pregnancy Loss Research Group, The Irish Centre for Fetal and Neonatal Translational Research University College Cork, Cork, Ireland. ${ }^{2}$ National Perinatal Epidemiology Centre, Department of Obstetrics and Gynaecology, University College Cork, Cork University Maternity Hospital, 5th floor, Postgraduate Study Room, 5S-30, Wilton, Cork T12 YE02, Ireland. ${ }^{3}$ The Irish Centre for Fetal and Neonatal Translational Research, Department of Obstetrics and Gynaecology, University College Cork, Cork, Ireland. ${ }^{4}$ School of Public Health, University College Cork, Cork, Ireland.

Received: 10 July 2018 Accepted: 15 April 2019

Published online: 09 May 2019

\section{References}

1. Jurkovic D, Overton C, Bender-Atik R. Diagnosis and management of first trimester miscarriage. BMJ. 2013;346:f3676.

2. Poulose $T$, Richardson R, Ewings P, Fox R. Probability of early pregnancy loss in women with vaginal bleeding and a singleton live fetus at ultrasound scan. J Obstet Gynaecol. 2006;26(8):782-4.

3. National Institute for Health and Care ExcellenceEctopic pregnancy and miscarriage: diagnosis and initial management. In. Edited by National Institute for Health and Care Excellence; 2012.

4. Royal College of Physicians of Ireland. Ultrasound Diagnosis of Early Pregnancy Miscarriage. In: National Clinical Guidelines in Obstetrics and Gynaecology. Republic of Ireland: Royal College of Physicians of Ireland, RCPI; 2010.

5. Royal College of Physicians of Ireland. The management of second trimester miscarriage. In: National Clinical Guidelines in Obstetrics and Gynaecology. Republic of Ireland: Royal College of Pysicians of Ireland, RCPI; 2017.

6. Royal College of Physicians of Ireland. Management of early pregnancy miscarriage. In: National Clinical Guidelines in Obstetrics and Gynaecology. Republic of Ireland: Royal College of Physicians of Ireland, RCPI; 2012.

7. Zinaman MJ, Clegg ED, Brown CC, O'Connor J, Selevan SG. Estimates of human fertility and pregnancy loss. Fertil Steril. 1996;65(3):503-9.

8. Wilcox AJ, Weinberg CR, O'Connor JF, Baird DD, Schlatterer JP, Canfield RE, Armstrong EG, Nisula BC. Incidence of early loss of pregnancy. N Engl J Med. 1988:319(4):189-94.

9. Everett C. Incidence and outcome of bleeding before the 20th week of pregnancy: prospective study from general practice. Br Med J. 1997; 315(7099):32-4.

10. Knudsen UB, Hansen V, Juul S, Secher NJ. Prognosis of a new pregnancy following previous spontaneous abortions. Eur I Obstet Gynecol Reprod Biol. 1991;39(1):31-6.

11. Morris A, Meaney S, Spillane N, O'Donoghue K. The postnatal morbidity associated with second-trimester miscarriage. J Matern-Fetal Neo M. 2016; 29(17):2786-90

12. Wyatt PR, Owolabi T, Meier C, Huang T. Age-specific risk of fetal loss observed in a second trimester serum screening population. Am J Obstet Gynecol. 2005;192(1):240-6.

13. Sotiriadis A, Makrydimas G, Papatheodorou S, loannidis JP. Expectant, medical, or surgical management of first-trimester miscarriage: a metaanalysis. Obstet Gynecol. 2005:105(5 Pt 1):1104-13.

14. Condous G, Kirk E, Syed A, Van Calster B, Van Huffel S, Timmerman D, Bourne T. Do levels of serum cancer antigen 125 and creatine kinase predict the outcome in pregnancies of unknown location? Hum Reprod. 2005:20(12):3348-54.

15. Zhang J, Gilles JM, Barnhart K, Creinin MD, Westhoff C, Frederick MM, National Institute of child health human development Management of Early Pregnancy Failure. A comparison of medical management with misoprostol and surgical management for early pregnancy failure. N Engl J Med. 2005; 353(8):761-9.

16. Luise C, Jermy K, May C, Costello G, Collins WP, Bourne TH. Outcome of expectant management of spontaneous first trimester miscarriage: observational study. BMJ. 2002;324(7342):873-5. 
17. Kim C, Barnard S, Neilson JP, Hickey M, Vazquez JC, Dou L. Medical treatments for incomplete miscarriage. Cochrane Database Syst Rev. 2017; (1):CD007223. https://doi.org/10.1002/14651858.CD007223.pub4.

18. Grimes DA. The morbidity and mortality of pregnancy: still risky business. Am J Obstet Gynecol. 1994;170(5 Pt 2):1489-94.

19. Kulier R, Fekih A, Hofmeyr GJ, Campana A. Surgical methods for first trimester termination of pregnancy. Cochrane Database Syst Rev. 2001;4: CD002900.

20. Black RE, Walker N, Laxminarayan R, Temmerman M. Reproductive, Maternal, Newborn, and Child Health: Key Messages of This Volume. In: Black RE, Laxminarayan R, Temmerman M, Walker N, editors. Reproductive, Maternal, Newborn, and Child Health: Disease Control Priorities, Third Edition (Volume 2). Washington (DC): The International Bank for Reconstruction and Development/The World Bank; 2016.

21. Neilson JP, Gyte GM, Hickey M, Vazquez JC, Dou L. Medical treatments for incomplete miscarriage (less than 24 weeks). Cochrane Database Syst Rev. 2010;3(1):CD007223.

22. Wiley MM. Using HIPE data as a research and planning tool: limitations and opportunities: a response. Irish J Med Sci. 2005;174(2):52-7.

23. O'Loughlin R, Allwright S, Barry J, Kelly A, Teljeur C. Using HIPE data as a research and planning tool. Irish J Med Sci. 2005;174(4):66.

24. Health Research and Information Division. Activity in acute public hospitals in Ireland annual report, 2012. In: Economic and Social Research Institute. Republic of Ireland: Economic and Social Research Institute; 2013.

25. Health Service Executive. Maternity and Infant Care Scheme2017 Available from: [http://www.hse.ie/eng/services/list/3/maternity/combinedcare.html].

26. Tulandi T, Barbieri RL, Falk SJ. Ectopic pregnancy: incidence, risk factors and pathology; 2016

27. Maconochie N, Doyle P, Prior S, Simmons R. Risk factors for first trimester miscarriage: results from a UK-population-based case-control study. BJOG. 2007;114(2):170-86.

28. Andersen AMN, Wohlfahrt J, Christens P, Olsen J, Melbye M. Maternal age and fetal loss: population based register linkage study. Br Med J. 2000; 320(7251):1708-12.

29. Royal College of Obstetricians and Gynaecologists. The management of early pregnancy loss. Addendum to GTG No 25 (Oct 2006). Republic of Ireland: RCOG Press; 2011.

30. Newbatt E, Beckles Z, Ullman R, Lumsden MA, Guideline development G Ectopic pregnancy and miscarriage: summary of NICE guidance. BMJ. 2012; 345:e8136.

31. Lane BF, Wong-You-Cheong JJ, Javitt MC, Glanc P, Brown DL, Dubinsky T, Harisinghani MG, Harris RD, Khati NJ, Mitchell DG, et al. ACR appropriateness criteria(R) first trimester bleeding. Ultrasound Q. 2013;29(2):91-6.

32. Health Service Executive. National Msicarriage Misdiagnosis Review. In: Health Service Executive. Republic of Ireland: Health Service Executive; 2011.

33. National Institute for Health and Care Excellence. Ectopic pregnancy and miscarriage: evidence update december 2014. In: A summary of selected new evidence relevant to NICE clinical gideline 154 'Diagnosis and initial management in early pregnancy of ectopic pregnancy and miscarriage'. UK: National Institute for Health and Care Excellence; 2014. p. 2012

34. Trinder J, Brocklehurst P, Porter R, Read M, Vyas S, Smith L. Management of miscarriage: expectant, medical, or surgical? Results of randomised controlled trial (miscarriage treatment (MIST) trial). Br Med J. 2006;332(7552):1235-8.

35. Graziosi GCM, Mol BWJ, Reuwer PJH, Drogtrop A, Bruinse HW. Misoprostol versus curettage in women with early pregnancy failure after initial expectant management: a randomized trial. Hum Reprod. 2004;19(8):1894-9.

36. Davis AR, Hendlish SK, Westhoff C, Frederick MM, Zhang J, Gilles JM, Barnhart K, Creinin MD, National Institute of child $H$, human development Management of Early Pregnancy Failure T. Bleeding patterns after misoprostol vs surgical treatment of early pregnancy failure: results from a randomized trial. Am J Obstet Gynecol. 2007;196(1):31 e31-7.

37. Muffley PE, Stitely ML, Gherman RB. Early intrauterine pregnancy failure: a randomized trial of medical versus surgical treatment. Am J Obstet Gynecol. 2002;187(2):321-5; discussion 325-326.

38. Weeks A, Alia G, Blum J, Winikoff B, Ekwaru P, Durocher J, Mirembe F. A randomized trial of misoprostol compared with manual vacuum aspiration for incomplete abortion. Obstet Gynecol. 2005;106(3):540-7.

\section{Ready to submit your research? Choose BMC and benefit from:}

- fast, convenient online submission

- thorough peer review by experienced researchers in your field

- rapid publication on acceptance

- support for research data, including large and complex data types

- gold Open Access which fosters wider collaboration and increased citations

- maximum visibility for your research: over $100 \mathrm{M}$ website views per year

At BMC, research is always in progress.

Learn more biomedcentral.com/submissions 